\title{
Evolutionary Conservation of Regulatory Elements in Vertebrate Hox Gene Clusters
}

\author{
Simona Santini, ${ }^{1}$ Jeffrey L. Boore, ${ }^{2}$ and Axel Meyer ${ }^{1,3}$ \\ ${ }^{7}$ Department of Biology, University of Konstanz, 78457 Konstanz, Germany; ${ }^{2}$ Department of Evolutionary Genomics, DOE \\ Joint Genome Institute, Lawrence Berkeley National Laboratory, and University of California, Berkeley, California 94720, USA
}

\begin{abstract}
Comparisons of DNA sequences among evolutionarily distantly related genomes permit identification of conserved functional regions in noncoding DNA. Hox genes are highly conserved in vertebrates, occur in clusters, and are uninterrupted by other genes. We aligned (PipMaker) the nucleotide sequences of the HoxA clusters of tilapia, pufferfish, striped bass, zebrafish, horn shark, human, and mouse, which are separated by approximately 500 million years of evolution. In support of our approach, several identified putative regulatory elements known to regulate the expression of Hox genes were recovered. The majority of the newly identified putative regulatory elements contain short fragments that are almost completely conserved and are identical to known binding sites for regulatory proteins (Transfac database). The regulatory intergenic regions located between the genes that are expressed most anteriorly in the embryo are longer and apparently more evolutionarily conserved than those at the other end of Hox clusters. Different presumed regulatory sequences are retained in either the $A \alpha$ or $A \beta$ duplicated Hox clusters in the fish lineages. This suggests that the conserved elements are involved in different gene regulatory networks and supports the duplication-deletioncomplementation model of functional divergence of duplicated genes.
\end{abstract}

[Supplemental material is available online at www.genome.org. The sequence data from this study have been submitted to GenBank under accession no. AF538976.]

Understanding the mechanisms that underlie gene regulation is one of the major goals of comparative genomics as well as developmental biology. The functions of cis-acting regulatory sequences that are located in noncoding regions of DNA are still not well understood (Clark 2001). Comparative DNA sequence analyses have become increasingly important since the high degree of conservation of regulatory elements was first recognized (e.g., Aparicio et al. 1995; Manzanares et al. 2000). The conservation of protein coding sequences even among evolutionarily distantly related organisms, presumably as a result of stabilizing selection, has been noted before (e.g., Hardison et al. 1997; Brenner et al. 2002). However, only a small portion of organisms' genomes encodes information for proteins. A large portion of the genome (up to 97\%, Onyango et al. 2000) is noncoding DNA, and a heretofore unknown part of it plays a role in regulating gene expression. The identification of functional elements in noncoding DNA sequences is often complicated by the fact that these elements are typically short (6-15 bp; e.g., Carroll et al. 2001) and reside at varying distances from their target gene. Functional elements tend to evolve at slower rates than nonfunctional regions, because they are subject to selection (Tagle et al. 1988; Hardison et al. 1997; Hardison 2000; Cliften et al. 2001). Due to this slower rate of evolution, comparisons among evolutionarily distantly related genome sequences provide a tool to identify functional regions in the sea of noncoding DNA (Tompa 2001, Blanchette and Tompa 2002), an approach that has been termed phylogenetic footprinting (Roth et al. 1998; Venkatesh et al. 2000; Cliften et al. 2001). Comparisons

\section{${ }^{3}$ Corresponding author.}

E-MAIL axel.meyer@uni-konstanz.de; FAX: 497531883018. Article and publication are at http://www.genome.org/cgi/doi/10.1101/ gr.700503. among closely related organisms, such as different species of Saccharomyces (Cliften et al. 2001) or Drosophila (Bergman and Kreitman 2001) have been successfully used to identify regulatory regions, and comparisons between humans and mice (evolutionary distance of approximately 80 million years; Pough et al. 1999) revealed many of the functionally relevant binding sites (Onyango et al. 2000). This is because of their high degree of conservation (on average 93.2\%; Wassermann et al. 2000).

Comparisons among closely related species revealed that many nonfunctional noncoding sequences also show a high degree of nucleotide identity, rendering the identification of DNA regions involved in gene regulation more difficult. However, in the alignment of long stretches of DNA sequences from evolutionarily distantly related species, conserved putative regulatory elements will stand out from the background of highly variable nonfunctional regions. This beneficial signal-to-noise ratio among more distantly related species permits the identification of putative regulatory elements.

The search for regulatory elements through comparative genomic approaches in Hox gene clusters promises to be particularly successful because their nucleotide sequence and function are extremely conserved in all vertebrates in which they have been studied. Hox genes code for transcription factors that are responsible for establishing the animal body plan early in embryonic development. They specify the position for developing fields along the anterior-posterior axis, and are characterized by a 183-bp motif, the homeobox, which encodes a conserved DNA binding structure, the homeodomain (reviewed in Gehring 1993). Within the homeobox gene family, Hox genes belong to a subfamily whose members are arranged in genomic clusters. Interestingly, their expression in terms of time of activation and boundary of expression along the anterior-posterior axis is "colinear" with the their chro- 
mosomal arrangement (e.g., Krumlauf 1994). Hox genes occur in strictly packed clusters, which aids their identification and alignment. It may not be surprising that Hox genes are highly conserved during evolution because of their importance in development in all animal phyla. Moreover, the degree of conservation in their coding sequences might suggest that their regulatory elements are largely invariant across even great evolutionary distances. There is some evidence for this expectation. One of the selective forces that keeps the genes of Hox clusters uninterrupted by reshuffling and insertion of other genes may stem from the fact that adjacent genes share common cis-regulatory elements (Peifer et al. 1987). Therefore, adjacent genes must remain closely linked, because translocations or insertions between them would deprive one of them of its cis-regulatory elements and, hence, be lethal mutations.

\section{RESULTS}

We compared four teleost species: tilapia (Oreochromis niloticus), pufferfish (Fugu rubripes), striped bass (Morone saxatilis), and zebrafish (Danio rerio) with two mammalian species (Homo sapiens and Mus musculus) and the horn shark (Heterodontus francisci) as an outgroup species. The Hox gene contents for all these species are compared in Figure 1. Highly conserved homeobox domains in the Hox genes permitted "anchoring" of the clusters with each other. Therefore, it was possible to align HoxA clusters on the basis of highly conserved regions of exons and thereby align evolutionarily distantly related genomic sequences to discover putative regulatory elements.

\section{Genomic Architecture of Hox A Clusters}

Comparisons of gene lengths and distances between genes of the HoxA clusters are shown in Figure 2. The single Hox cluster region of the cephalochordate amphioxus (haploid DNA content: $\mathrm{C}=0.59 \mathrm{pg}$; Ohno and Atkin 1966) spans over $400 \mathrm{~kb}$ (Garcia-Fernandez and Holland 1994; Ferrier et al. 2000), but the HoxA clusters of vertebrates that have been studied are considerably smaller. In the shark $(\mathrm{C}=7.25 \mathrm{pg}$, Stingo et al. 1989), the HoxA region is only approximately $110 \mathrm{~kb}$ long (AF224262 and AF479755). In this species, the cluster was previously named HoxM, but is the ortholog of HoxA (Kim et al. 2000). In humans ( $C=3.50 \mathrm{pg}$; Tiersch et al. 1989), the Hox A cluster is $110 \mathrm{~kb}$ long (AC004079, AC004080, and AC010990), in the mouse $(C=3.25$ pg; Vinogradov 1998; Asif et al. 2002) it is $105 \mathrm{~kb}$ (AC021667), in the tilapia ( $\mathrm{C}=0.99 \mathrm{pg}$; Hinegardner 1976) the HoxA $\alpha$ cluster is $100 \mathrm{~kb}$ (AF533976), in the pufferfish $(\mathrm{C}=0.40 \mathrm{pg}$; Brenner et al. 1993) the HoxA $\alpha$ is $64 \mathrm{~kb}$ (JGI public database), in the zebrafish $(\mathrm{C}=1.75 \mathrm{pg}$; Vinogradov 1998) the HoxA $\alpha$ is $62 \mathrm{~kb}$ (AC107365) and the HoxA $\beta$ is $33 \mathrm{~kb}$ (AC107364). The HoxA cluster of the mouse shows an even base composition, whereas for all other genomes examined the base composition of the HoxA clusters is AT-biased (Table 1).

The available striped bass $(\mathrm{C}=0.89 \mathrm{pg}$, Hinegardner 1976) sequence does not cover the entire cluster, but only the region from $H o x \mathrm{~A} 10 \alpha$ to $H o x \mathrm{~A} 4 \alpha$. The region HoxA9 $\alpha$ to HoxA $4 \alpha$ in striped bass is $24 \mathrm{~kb}$ long (AF089743); the homologous region in the tilapia HoxAa cluster is $23 \mathrm{~kb}$, in the pufferfish HoxAa cluster it is approximately $20 \mathrm{~kb}$, and in the zebrafish HoxA $\alpha$ cluster it is approximately $19 \mathrm{~kb}$ (the zebrafish HoxA $\beta$ does not contain genes 4,5 , and 7, so therefore cannot be evaluated). In the shark, human, and mouse clus- ters the region HoxA9 to HoxA4 is approximately $36 \mathrm{~kb}$. In agreement with the view that Hox clusters are reduced in size in vertebrates, this part of the amphioxus cluster is approximately $135 \mathrm{~kb}$ long (Fig. 2).

Genome sizes and lengths of the HoxA clusters seem to be correlated (Fig. 3). Lengths of Hox clusters have been previously shown to be independent of the pattern of gene loss among several fish species (Aparicio et al. 1997; Snell et al. 1999; Chiu et al. 2002). When the same genes are retained, the architecture of HoxA clusters is generally conserved among the species under examination; this holds true both in regard to relative lengths not only of orthologous genes among species, but also of spacing between genes, that is, the length of intergenic regions (Fig. 2).

There is increasing evidence for a fish-specific genome duplication that was shared by all (or most) ray-finned fishes (e.g., Amores et al. 1998; Wittbrodt et al. 1998; Taylor et al. 2001). This genome duplication also caused an initial doubling (and some secondary lineage-specific losses) of the number of Hox clusters from four to eight. So that, for example, two copies of the initial HoxA cluster resulted in the HoxA $\alpha$ and the HoxA $\beta$ clusters, which are now expected to be found in all (or most) ray-finned fishes. Independent gene losses in Hox clusters have happened in different species of fishes (Fig. 2).

The pufferfish HoxA $\alpha$ cluster was initially thought to lack HoxA7 $\alpha$ (Aparicio et al. 1997), and it was hypothesized that this loss, together with the loss of other members of the entire paralogy group 7 genes (Aparicio et al. 1997), could have been responsible for the absence of ribs and pelvic fins and girdle in this group of fishes (Holland 1997; Meyer 1998; Prince et al. 1998; Meyer and Malaga-Trillo 1999). Our comparisons show conservation of HoxA7 $\alpha$ exons in pufferfish, with the exception of a 84-bp deletion in the homeobox in exon 2. However, the observation that the homeodomain is lacking its central and most conserved part might argue that in pufferfish the HoxA7 $\alpha$ gene is a pseudogene.

The zebrafish A $\alpha$ cluster lacks HoxA7 $\alpha$ and contains only a fragment of exon 2 of HoxA10 $\alpha$. It also lacks HoxA $2 \alpha$ (Amores et al. 1998), but the cluster region corresponding to both HoxA $2 \alpha$ exons, the promoter, and the intron still shows nucleotide conservation, suggesting that its loss was a relatively recent event in the zebrafish lineage. The zebrafish $A \beta$ cluster lacks the HoxA1 $\beta$ and HoxA3 $\beta, \operatorname{HoxA} 4 \beta, H o x \mathrm{~A} 5 \beta$, and Hox $\mathrm{A} 7 \beta$ genes. In zebrafish, the $Н$ ox $\mathrm{A} \beta$ cluster has been subject to more losses of genes than the HoxA $\alpha$ cluster. Alternatively, the Hox5, 4, and 3 genes could have been lost in a single event in ${ }_{0} \times \mathrm{A} \beta$ cluster. The only genes absent in the HoxA $\alpha$ cluster, but present in the HoxA $\beta$ cluster belong to the Hox10 and Hox2 paralogy groups.

Tilapia has an almost complete HoxA $\alpha$ cluster, in terms of presence of Hox genes, and no lineage-specific gene losses relative to other teleost fishes were observed. The Tilapia $\operatorname{Hox} \mathrm{A} \alpha$ cluster retains the $\operatorname{Hox} 2,7$, and 10 genes, which are absent in the zebrafish $\operatorname{Hox} \mathrm{A} \alpha$ cluster. Figure 1 summarizes the specific losses of Hox genes in different fish lineages. We also have preliminary evidence for the presence of a $H o x \mathrm{~A} \beta$ cluster in tilapia (HoxA2 $\beta$ and HoxA3 $\beta$; Malaga-Trillo and Meyer 2001). The increased gene loss of the $H o x A \beta$ cluster compared to the HoxA $\alpha$ cluster known from zebrafish may also be repeated in the tilapia genome.

\section{Alignment of Nucleotide Sequences}

All Hox clusters were screened with RepeatMasker to highlight interspersed repeats. There is a complete absence of any kind

\section{Genome Research




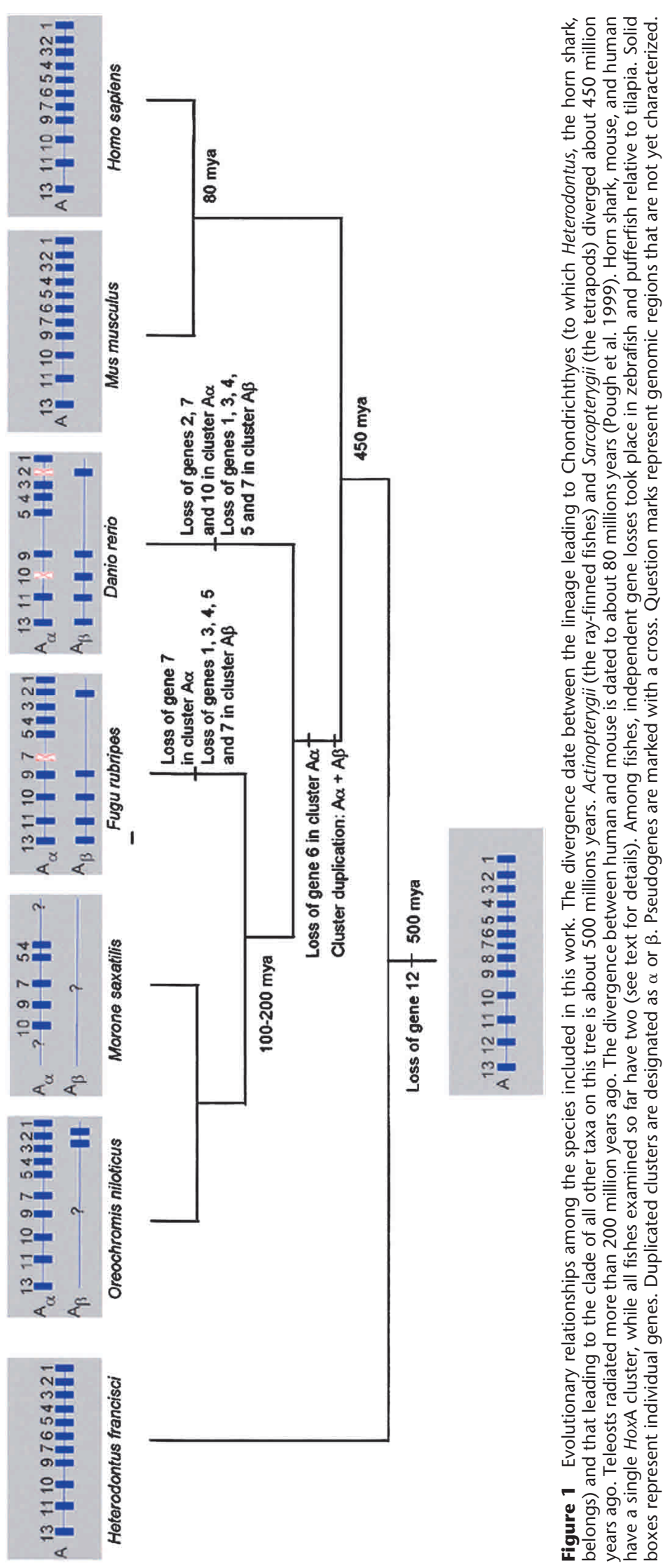



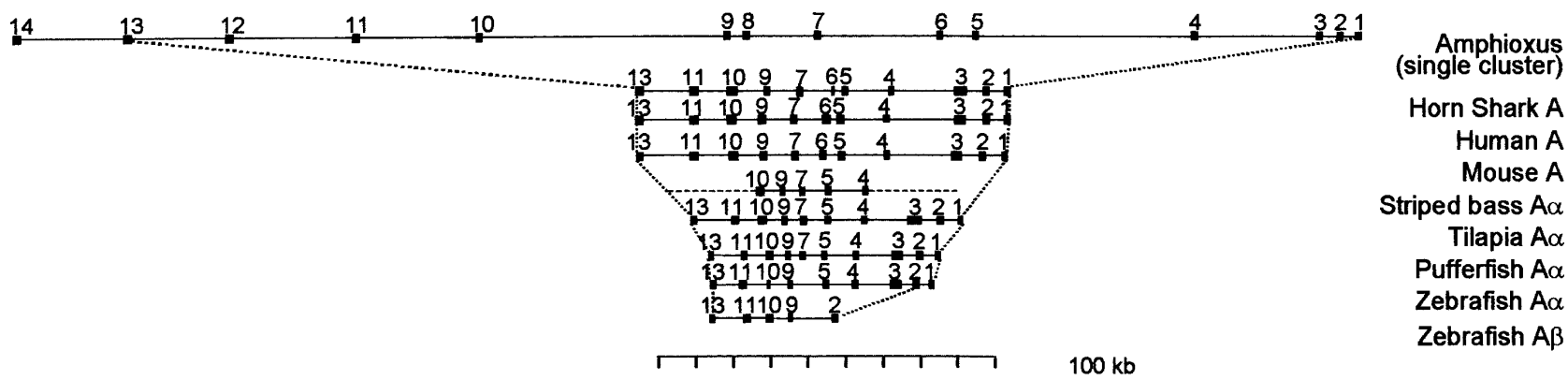

Figure 2 Relative sizes of HoxA clusters. Boxes represent individual genes. The duplicated $\alpha$ and $\beta$ clusters are shown only for zebrafish. The alignable portion of the pseudogenes HoxA7 $\alpha$ of pufferfish, HoxA2 $\alpha$ and HoxA10 $\alpha$ of zebrafish are shown as well.

of long repeats between genes of the HoxA clusters in all the examined species. We compared the nucleotide sequence of HoxA homologous genes from HoxA of tilapia, pufferfish, striped bass, shark, human, and mouse clusters, and both HoxA $\alpha$ and $H o x \mathrm{~A} \beta$ clusters from zebrafish. In the Pip output (Fig. 4), coding regions are shown with a blue background, introns in yellow, and conserved noncoding sequences (CNSs; Loots et al. 2000) not previously described in the literature in green. The sequence regions in red are conserved regulatory regions that have been previously described in literature. As expected, coding sequences show a particularly high degree of similarity, especially in the second exon (above $75 \%)$, which contains the homeobox, while introns are generally less conserved and cannot be aligned for long regions.

\section{Identification of CNSs}

Several stretches of sequence outside of the recognized coding regions of the Hox genes are highly conserved in all species examined (Fig. 4; Table 2). These CNSs were maintained for a period of about 500 million years of evolution. The fraction of CNSs for each intergenic region for the HoxA clusters is shown in Table 3. Interestingly, several $5^{\prime}$ and $3^{\prime}$ untranslated regions adjacent to the Hox genes of the clusters are conserved as well, suggesting that they may play an important role in the transcriptional regulation of the genes that they are flanking. A summary of the identified conserved regions is shown in Table 2. All identified CNSs have been tested individually by using BLASTN to exclude their presence in other positions of the genomes. No matches have been found to sequences outside the Hox clusters (at the significance threshold of $\mathrm{E}$ value $<0.01$ ). Several stretches of sequence involved in the regulation of Hox genes have been previously described in the literature (column 11 in Table 2), and these known regulatory sequences were also identified by our method.

The intergenic regions between genes located $3^{\prime}$ in the clusters are better conserved than those between genes lo-

Table 1. Percent Base Composition of the HoxA Clusters

\begin{tabular}{lcccc}
\hline Species & $\% \mathrm{~A}$ & $\% \mathrm{C}$ & $\% \mathrm{OG}$ & $\% \mathrm{~T}$ \\
\hline Tilapia & 28.356 & 21.166 & 20.981 & 29.496 \\
Pufferfish & 28.476 & 21.398 & 21.093 & 29.033 \\
Zebrafish $\alpha$ & 31.231 & 18.816 & 18.378 & 31.574 \\
Zebrafish $\beta$ & 32.891 & 18.552 & 16.876 & 31.680 \\
Horn shark & 31.169 & 18.783 & 18.666 & 31.382 \\
Human & 31.169 & 18.783 & 18.666 & 31.382 \\
Mouse & 24.827 & 24.778 & 25.271 & 25.124 \\
\hline
\end{tabular}

cated $5^{\prime}$ in the cluster (Fig. 5; Table 3; and the alignment in the Supplementary data files available online at www.genome.org). The total number of conserved nucleotides (over $60 \%$ identity) is significantly higher ( $P=0.007$; Fig. 5$)$ in the intergenic regions in the $3^{\prime}$ end of the cluster, and the detected CNSs are longer here.

\section{Description of Some Putative Regulatory Elements}

Due to the nature of cis-regulating elements, which can be as short as 6 bp (Hardison et al. 1997), we were interested in finding where such sequences reach the highest degree of conservation for even a small number of nucleotides.

The first part of the intron of HoxA11 $\alpha$ (51 bp) of the tilapia sequence is over $80 \%$ identical among tilapia, pufferfish, zebrafish $A \alpha$ and $A \beta$, horn shark, humans, and the mouse (data for this region in striped bass are not available). The fragment presents the consensus homeodomain binding sites HB1 located in the intron of the mouse genes HoxA4 and 7 (Haerry and Gehring 1996). The HB1-element consists of three homeodomain binding sites (HB1), and it is an evolutionary conserved DNA sequence previously described from the intron of HoxA7 (Haerry and Gehring 1996), in the leader (putative autoregulatory element) of its Drosophila homolog $U b x$ and in the introns of the paralogy group 4 Hox genes in medaka, chicken, the mouse, and humans (Morrison et al. 1995). The HB1 element binds Drosophila CAD homeoprotein and CDX-1, its homolog in the mouse, and it therefore is supposed to be a target for various homeodomain proteins in both vertebrates and invertebrates. Our comparative analyses show that the HB1 element is present not only in the introns of HoxA 4 and 7 as already described in the literature, but also in the intron of HoxA11 in the HoxA $\alpha$ cluster of all the species examined. Interestingly, it is also present in the intron of HoxA11 $\beta$ of zebrafish.

The region responsible for the cis-regulation of the HoxA7 gene has previously been described by Knittel et al. (1995) as an enhancer located $1.6 \mathrm{~kb}$ upstream of the coding sequence in human and mouse. These authors hypothesized that another proximal regulatory element can cooperate in the expression of HoxA7. Immediately upstream of the HoxA7 gene we highlighted a 185 bp stretch with more than $84 \%$ sequence identity. Our comparison (Fig. 4) shows that there are several completely conserved sequences within this fragment, characterized by the short motif GTAAA. This long conserved region might be the regulatory element that Knittel et al. (1995) hypothesized.

In the intron of the HoxA7 the HB1-element has a sequence identity of over $80 \%$ among the examined species.

\section{Genome Research


The region immediately upstream of the HoxA5 gene (490 bp) is between $70 \%$ and $85 \%$ similar. The RARE elements described as "box c" and "box d" by Odenwald et al. (1989) in humans and the mouse were recognized (Fig. 6). These elements are present, with minor variations, among all Hox genes of paralogy group 5, and are known regulatory binding sites in the mouse Hox 1.3 (HoxA5) (Odenwald et al. 1989). The conservation percentages within the single boxes are $88 \%$ for the "box c" and 96\% for the "box d".

Downstream of the HoxA5 gene $(1.3 \mathrm{~kb})$ a region of 259 bp has an average similarity of $90 \%$, with two $100 \%$ identical stretches of 25 and $33 \mathrm{bp}$ length. The motifs found in this region are ATGAAT (with a repeat following after $13 \mathrm{bp}$ ), ATAAA, $(\text { AAGT })_{2}$, and (ACATA $)_{2}$. The motifs identified by our comparisons are similar to those described as binding sites of the paired domain of the Pax genes (Epstein et al. 1994) and also of the Ultrabithorax gene of Drosophila (Ekker et al. 1991). This extremely conserved region was not previously described as being involved in Hox 5 and 4 regulation, but the nature and conservation of the long stretches highlighted through this comparison suggest that it might be a good candidate region for functional tests.

Upstream of the HoxA4 gene we identified a stretch 154 bp that has a similarity of $85 \%$ containing a RARE element (17 bp) that is part of the HoxA4 promoter, described by Doerksen et al. (1996). In the intron of gene HoxA4 a 68 bp long stretch was found containing the previously described HB1 element (Haerry and Gehring 1996).

Downstream of HoxA4 (1.7 kb) a 127 bp-long sequence is, on average, $78 \%$ conserved with a 26 bp-long stretch that is $96 \%$ conserved containing the AAATAAAA (position 63576-63583) and ATTTAA motifs and a 16-bp stretch that is

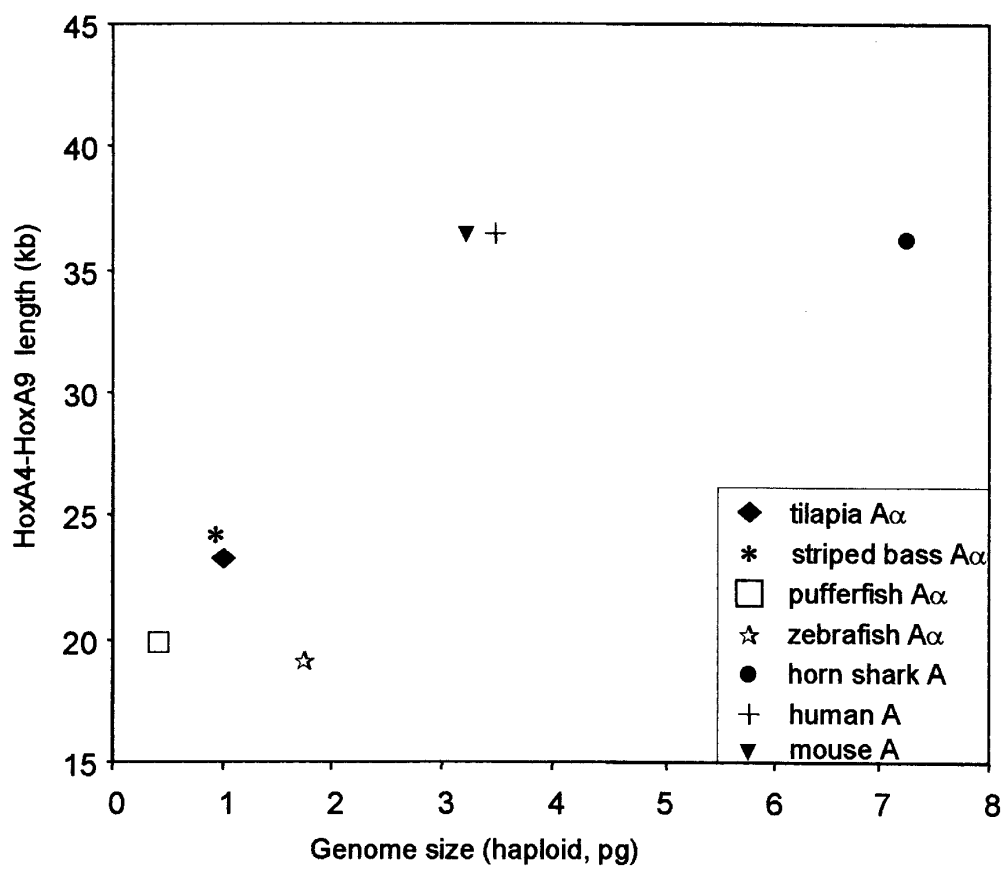

Figure 3 Relationship between genome size and length of the portion HoxA4 to HoxA9 of HoxA clusters. The length of HoxA clusters is correlated $(P=0.06)$ with genome size expressed as $C$ value. The HoxA $\alpha$ cluster lengths are shown. To be able to include also striped bass (HoxA cluster sequence is available only from HoxA4 $\alpha$ to HoxA10 $\alpha$ ) and zebrafish (HoxA $\alpha$ cluster lacks $H o x A 10 \alpha$ ) into the analysis, only the length of the HoxA4 to HoxA9 portion of the cluster is shown.
94\% conserved containing the motif TTTTATTT (position 63882-63889). This is possibly a palindromic sequence for the complementary one in position 63576. Palindromes are frequently associated with regulatory elements (Chu et al. 2001).

Immediately upstream of the gene HoxA2 we found a 352-bp region that is $85 \%$ conserved that constitutes part of the HoxA2 promoter described by Tan et al. (1992) in the mouse HoxA cluster. The Krx2O element and the nearby "box a", described by Nonchev et al. (1996) as being involved in HoxA2 trans-activation in mouse, and present in tilapia HoxA cluster (Fig. 7A), was not identified by our alignment. To confirm this result we searched specifically for these elements in zebrafish, pufferfish, and horn shark clusters, but could not identify them.

\section{Identification of Previously Described Functional Elements}

Extensive searches of the transcription factor database (Transfac) revealed that several of these short $100 \%$ conserved sequences match previously described transcription factor binding sites (column 12 in Table 2). The matches most frequently obtained are: nuclear factor NF1 binding sites (Rossi et al. 1988), abdominal B ( $\mathrm{AbdB}$ ) homeobox gene binding sites (Ekker et al. 1994), $C d x$ A homeobox gene binding sites (Margalit et al. 1993), and murine homeodomain binding sites (Catron et al. 1993).

Several of the most conserved sequences are highly similar to known transcription factors binding site motifs. One of these is the $K r \times 20$ binding site, which was found in humans, the mouse, pufferfish, and tilapia clusters (Fig. 7A). Krx20 binding sites have been described by Nonchev et al. (1996) as being involved in HoxA2 regulation as an $\mathrm{r} 3 / \mathrm{r} 5$ enhancer that upregulates the expression of those genes in rhombomere3/rhombomere5, where Krx2O is expressed in humans, chicks, the mouse, and pufferfish. The $K r \times 20$ binding site is 9 bp long and occurs around $2 \mathrm{~kb}$ upstream of the genes HoxA2 and HoxB2, with a high degree of conservation (Fig. 7A). It is closely followed by a $12 \mathrm{bp}$ long conserved sequence motif called "box a", which is highly similar to "box1", the corresponding element associated with Krx20 binding site in cluster B (Fig. 7B). Box 1 is required for $\mathrm{r} 3 / \mathrm{r} 5$ enhancer function in transgenic mice (Vesque et al. 1996).

\section{DISCUSSION}

Our analyses confirm the value of comparative evolutionary genomic approaches in the identification and description of regulatory elements in genomes. We expect that this type of analysis will help to increase the knowledge base about the characteristics, evolutionary conservation, and the position of functional elements with respect to the genes that they control.

We conducted several comparative analyses of the entire HoxA clusters for seven species of vertebrates. We compared the position and nucleotide sequence of the genes that constitute the HoxA $\alpha$ cluster from O. niloticus with those of the other species in this study. The complete absence of long repetitive elements supports the idea that one of the selective forces keeping 


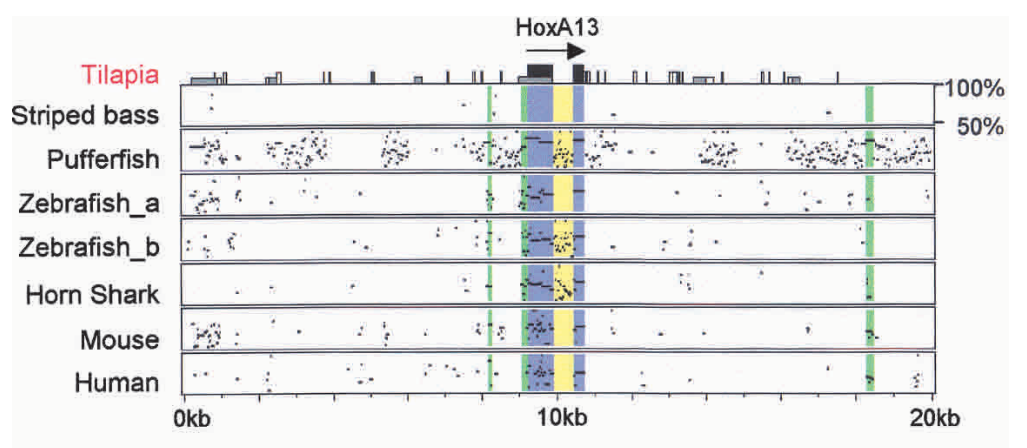

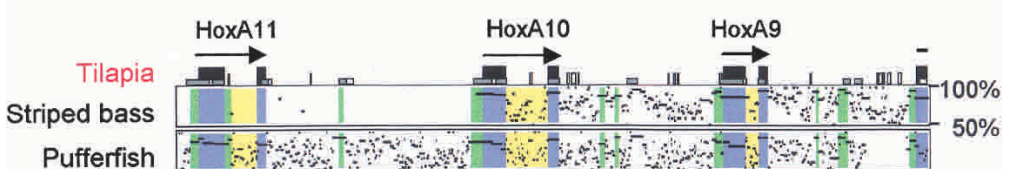

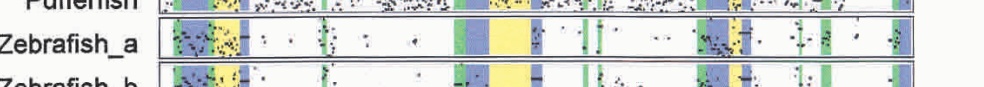

Zebrafish_b ش4.

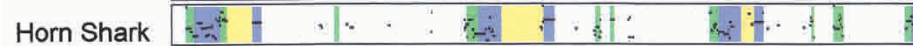

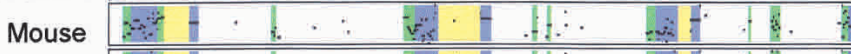

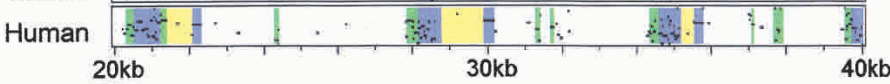

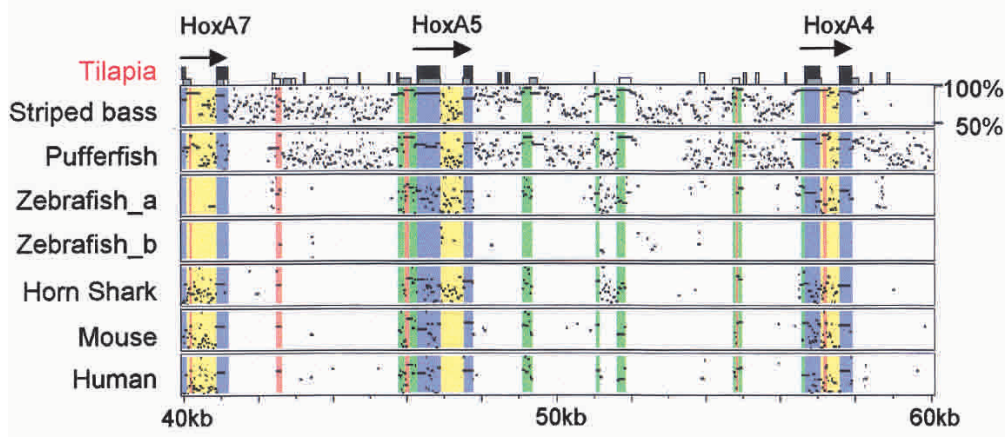

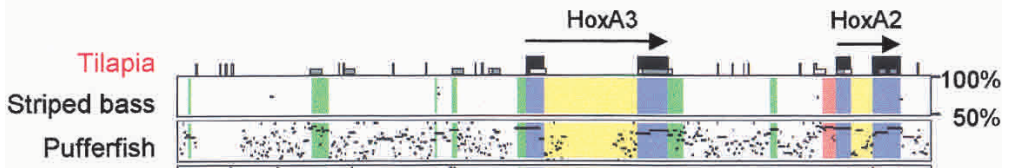

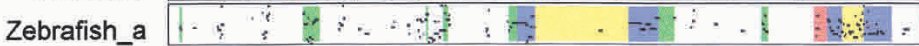

Zebrafish_b

Horn Shark

Mouse

Human

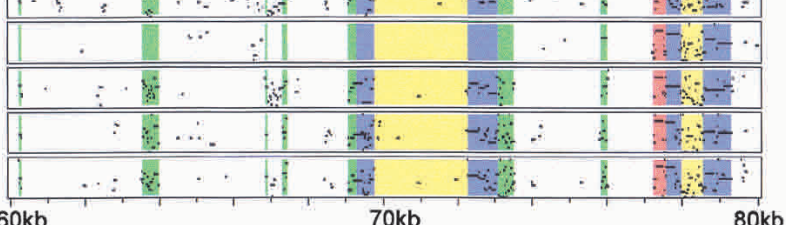

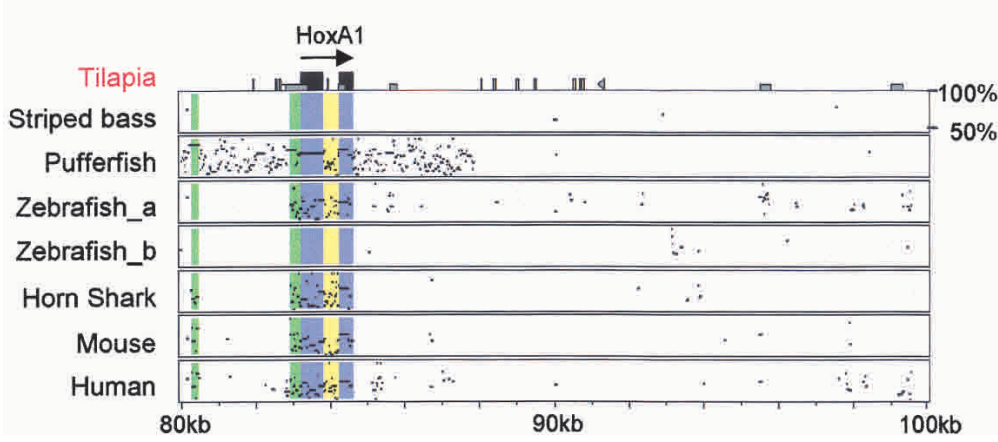

the genes in Hox clusters tightly arranged stems from the fact that adjacent genes share common cis-regulatory elements. Interestingly, it has been suggested that repetitive elements are frequently involved in chromosomal rearrangement processes, such as inversion, translocation, and excision (Moran et al. 1999; Tomilin 1999). Hence, the absence of repetitive elements might be the result of selections against them, to reduce the risk of events that may interrupt Hox cluster compactness.

\section{Degree of Conservation of Intergenic Regions}

Teleost fishes, horn shark, and mammals were included in this study, to ensure comparisons of distantly related genomes, because their lineages separated approximately 450-500 millions years ago (e.g., Pough et al. 1999). Our comparative analyses were directed toward identifying conserved blocks of nucleotides among evolutionarily distantly related species that might be cis-acting sites for Hox gene-regulating factors. Intergenic regions show varying degrees of conservation (Table 3). Intergenic spaces between genes located $3^{\prime}$ in the clusters are significantly more conserved than those in the $5^{\prime}$ portion of the clusters (Fig. 5; Table 3). This pattern might be explained by the different Hox genes' expression patterns during development. Genes located in $5^{\prime}$ position in the cluster are expressed more posteriorly in the embryo and later in its development, while genes located in position 3 ' in the cluster are expressed more anteriorly in the embryo and earlier in its development (Duboule and Dollé 1989). Genes located 3' in the cluster, namely Hox $1-4$, are expressed in the developing hindbrain. Their regulatory elements are evolutionarily highly conserved as was demonstrated through transgenic experiments (e.g., Frasch et al. 1995; Manzanares et al. 2000). The intergenic regions of Hox genes 3' in the clusters are responsible for the activation of the first and more rostral genes to be expressed during development, and therefore their extreme conservation might be necessary for the correct activation of the subsequent Hox expression system. We found a significant

Figure 4 Pip output of the comparison of tilapia $\operatorname{HoxA} \alpha$, striped bass $H o x A \alpha$, pufferfish $\operatorname{HoxA} \alpha$, zebrafish $\operatorname{HoxA} \alpha$ and $A \beta$, horn shark HoxA, human HoxA, and mouse HoxA clusters. The tilapia sequence has been used as reference sequence. Kilobase $(\mathrm{kb})$ markings are based on the tilapia sequence. Blue background indicates coding regions, yellow indicates introns, red indicates conserved noncoding sequences (CNSs) previously described in literature, and the green background indicates heretofore undescribed CNSs. Horizontal arrows indicate the direction of transcription, tall black boxes show exons, short open boxes indicate a $\mathrm{CpG} / \mathrm{GpC}$ ratio between 0.6 and 0.75 , and short gray boxes indicate a $\mathrm{CpG} / \mathrm{GpC}$ ratio over 0.75 . Interspersed repeat elements are shown as triangles (e.g., in position $91 \mathrm{~kb}$ ).

\section{Genome Research}




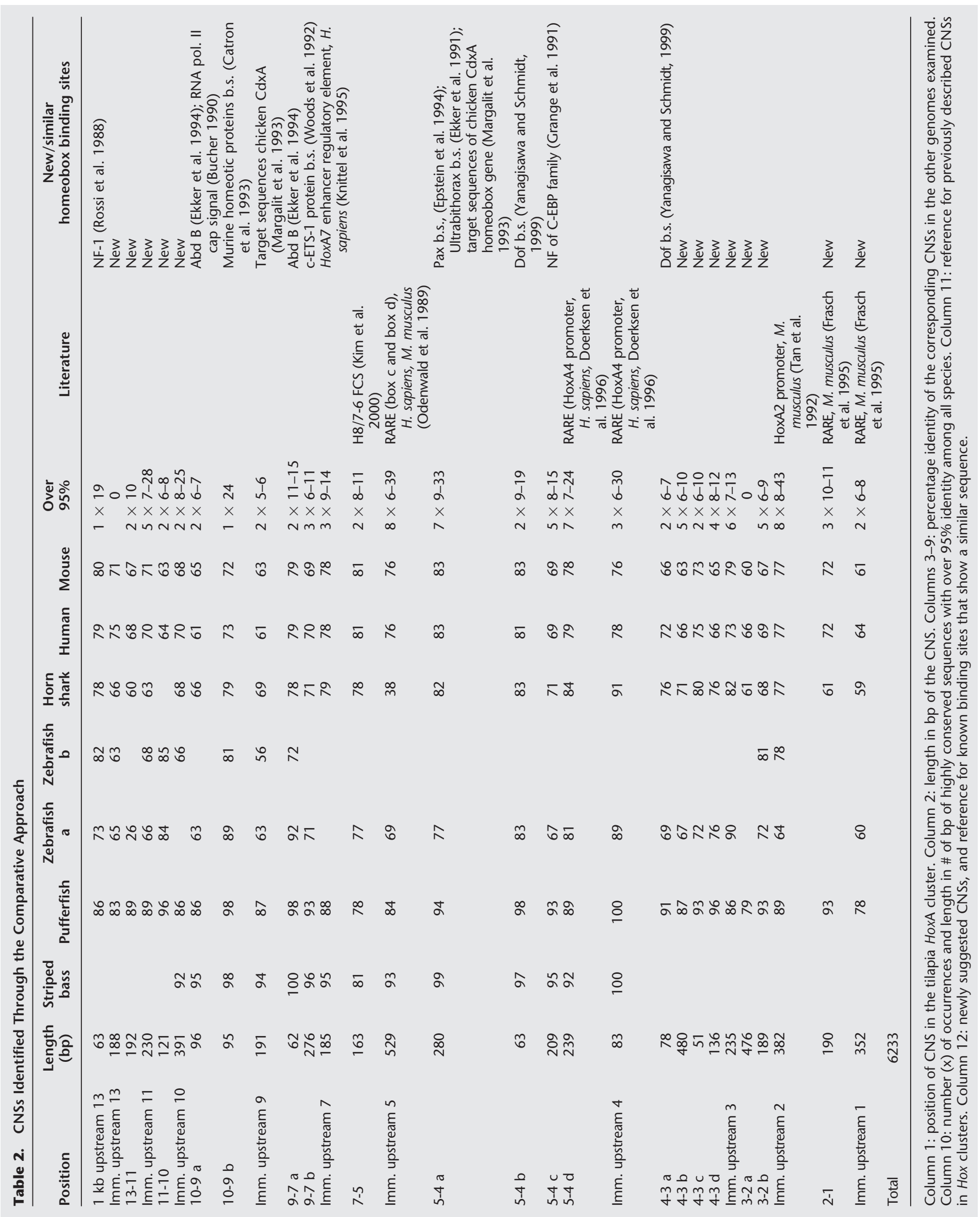


Table 3. Base Conservation of the Intergenic Regions of the Tilapia HoxA Cluster

\begin{tabular}{lcccc}
\hline $\begin{array}{l}\text { Intergenic } \\
\text { fragment }\end{array}$ & $\begin{array}{c}\text { \% of total } \\
\text { noncoding } \\
\text { bases }\end{array}$ & $\begin{array}{c}\text { \% identified } \\
\text { as CNS }\end{array}$ & $\begin{array}{c}\text { \% described } \\
\text { in literature }\end{array}$ & $\begin{array}{c}\text { \% of } \\
\text { total } \\
\text { CNSs }\end{array}$ \\
\hline Evx-13 & 13 & 3 & 0 & 4 \\
$13-11$ & 14 & 4 & 0 & 7 \\
$11-10$ & 9 & 9 & 0 & 8 \\
$10-9$ & 7 & 9 & 0 & 6 \\
$9-7$ & 6 & 13 & 12 & 8 \\
$7-5$ & 8 & 14 & 4 & 11 \\
$5-4$ & 13 & 10 & 4 & 14 \\
$4-3$ & 17 & 9 & 0 & 16 \\
$3-2$ & 7 & 23 & 10 & 17 \\
$2-1$ & 6 & 14 & 14 & 9 \\
\hline
\end{tabular}

Column 1: considered intergenic fragment. Column 2: percentage of total noncoding bases of the tilapia HoxA cluster represented by the intergenic region. Column 3: percentage of the intergenic fragment identified as CNS by our analyses. Column 4 : percentage of the intergenic fragment previously described in literature as involved in Hox genes regulation. Column 5: percentage of total CNSs present in this particular intergenic fragment.

increase in length of the CNSs between pairs of $3^{\prime}$ genes compared to intergenic regions of genes located $5^{\prime}$ and not involved in hindbrain segmentation (Fig. 5; $P=0.007$ ).

In our analyses we also included the noncoding regions upstream of the Hox 13 gene and downstream of the Hox 1 gene. Intergenic regions between two Hox genes contain regulatory elements for genes both upstream and downstream (e.g., Peifer et al. 1987). In addition, also if the region upstream of the Hox 13 gene contains only regulatory elements for this gene, and the same holds true for the region downstream of the Hox 1 gene, the trend of increasing length of CNSs from $5^{\prime}$ to $3^{\prime}$ within intergenic regions is still significant.

\section{Search for Regulatory Sequences}

Several conserved noncoding regions have been identified in this study. All the identified CNSs are specific to Hox clusters (no matches with any other region of the genome when aligned by using BLASTN).

Some of these regions reside immediately $5^{\prime}$ and 3 'of the genes of the Hox clusters, and this feature is generally related to functional roles (e.g., reviewed by Maconochie et al. 1996). Promoters are located immediately $5^{\prime}$ upstream of genes (e.g., HoxA2 promoter; Tan et al. 1992) and RAREs are located $3^{\prime}$ of the regulated gene (e.g., Frasch et al. 1995). However, the largest part of conserved regions we found is located between two genes and is quite distant (by 1-5 kb; column 1 in Table 2) from both. Thus, these regions are the most interesting, because cis-regulatory regions in Hox clusters are located in positions that are intermediate between the genes they regulate. An example for this phenomenon is an element named H8/7-6 FCS (Kim et al. 2000) that was shown by Kim et al. (2000) to exist in all four clusters of mammals and shark that they compared. We showed that this element is also present in the HoxA $\alpha$ cluster of fishes (Fig. 4;
Table 2). This element is located $1.2 \mathrm{~kb}$ downstream of the HoxA7 $\alpha$ gene and $3.6 \mathrm{~kb}$ upstream of the HoxA5 $\alpha$ gene in tilapia (Table 2). These Hox genes are involved in controlling the development of the branchial region (Krumlauf 1994). The conservation of the nucleotide sequence and relative position in all clusters examined so far makes this element an excellent candidate for an evolutionary conserved cisregulatory element. Table 2 lists several other CNSs located between two genes that might contain cis-regulatory elements. We could not locate the Krx20 and "box a" in any CNS in our alignment, because the Krx20 binding site and "box a" are short sequences that are not embedded in a block of at least $50 \mathrm{bp}$ with a conservation of at least $60 \%$ in a minimum of four clusters. In this particular case, our criteria defining CNSs were too strict. Furthermore, HoxA1 RARE elements described by Langston et al. (1997) could not be identified, because the region downstream of HoxA $1 \alpha$ was not available for most of the sequences and, hence, the alignment did not fit the above-mentioned criteria for defining CNSs.

All except one of the CNSs identified through our comparisons are present in at least one of the zebrafish HoxA clusters and some in both of them (Table 2). A specific CNS is generally conserved in the one of the two zebrafish HoxA clusters that still retains the gene located downstream of its position, that is, the CNS upstream of HoxA10 is present only in $H o x \mathrm{~A} \beta$ cluster, which retains the gene HoxA10, and was lost in HoxA $\alpha$ cluster, which does not have the Hox10 gene. The same pattern is found in CNSs located upstream of the HoxA5, 4 , and 3 genes that are present only in the HoxA $\alpha$ cluster, which still retains those genes. The CNS found immediately upstream of HoxA7 and previously described by Knittel et al. (1995) as an enhancer of HoxA7 in humans and the mouse is absent from both zebrafish Hox clusters. This is particularly

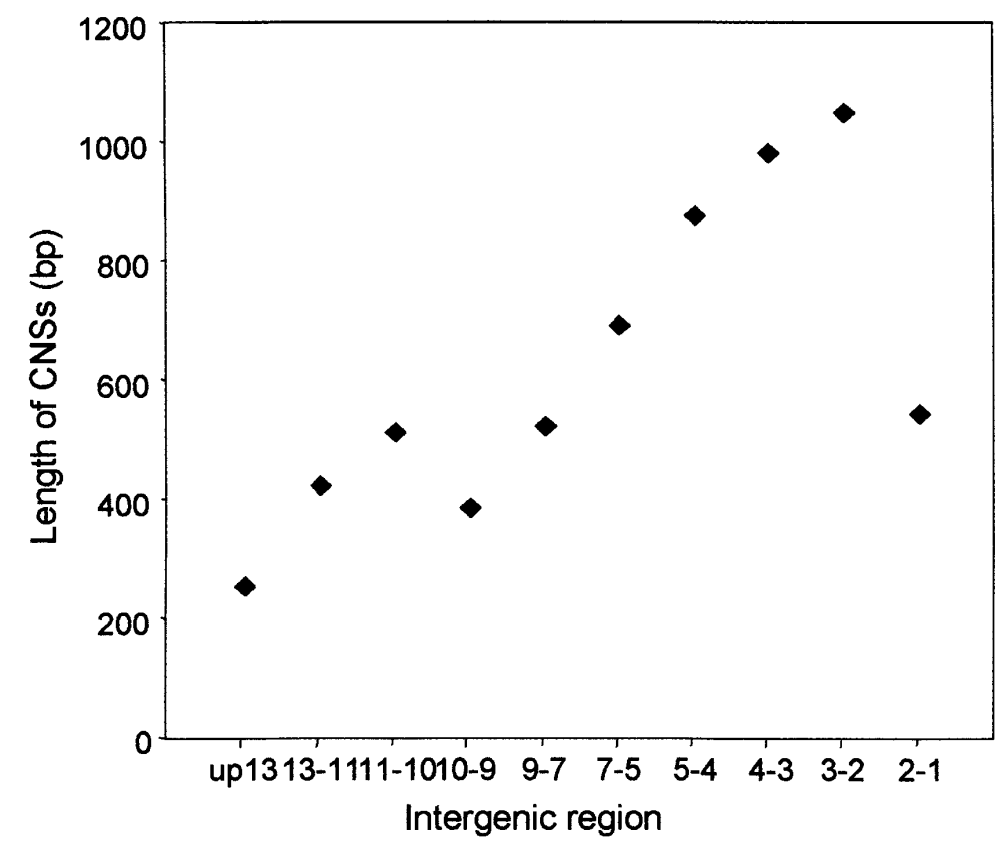

Figure 5 Total lengths of CNSs for each intergenic region. The intergenic regions located $3^{\prime}$ in the cluster are better conserved than those between genes located $5^{\prime}$ in the cluster. The graph shows the number of conserved bases (CNS as defined in text) per intergenic region. There is a significant relationship between the number of conserved bases per intergenic region and the position of the region in the cluster $(P=0.007)$.

\section{Genome Research


Tilapia Stiped bass Pufferfish

Zebrafish $\alpha$ Horn shark

Human

Mouse
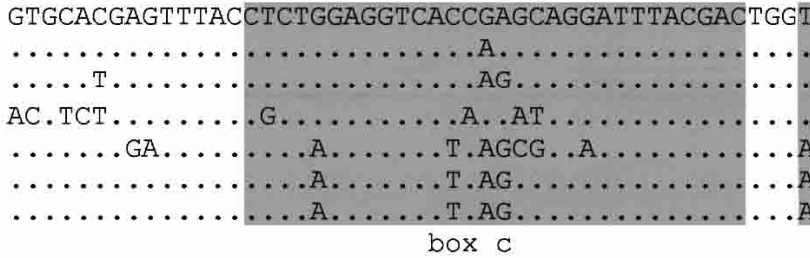

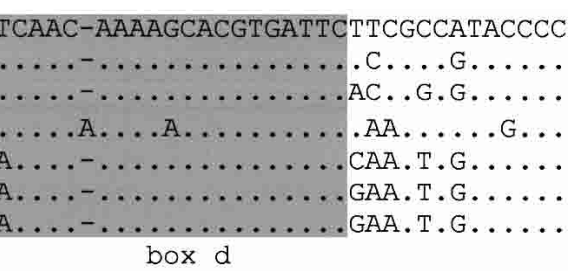

box d

Figure 6 Alignment of known RARE elements. The alignment shows the RARE element described as "box c" and "box d" (Odenwald et al. 1989) immediately upstream of the HoxA5 genes. In zebrafish, the RARE element is present only in HoxA $\alpha$ cluster (indicated as zebrafish $\alpha$ ).

interesting, because the HoxA7 gene was lost during zebrafish genome evolution. Also, the CNS located in the intergenic region between the HoxA3 and 2 genes and indicated as 3-2a in Table 2 is absent from both zebrafish clusters. This particular CNS has one of the lowest overall conservation levels, with no stretches being over 95\% identity. These observations enforce the possibility that the CNSs we identified are actually involved in regulatory functions.

The duplication-deletion-complementation model (DDC; Force et al. 1999) proposes that the two duplicated gene copies retain different sets of regulatory elements, and therefore, presumably different function. The set of functions of the initial gene might be divided, "subfunctionalized," by the two duplicated "daughter" copies of the gene. The Hox13, 11, and 9 genes are each present in two copies in the zebrafish genome, in the HoxA $\alpha$ and $A \beta$ clusters. The CNSs upstream of these genes are also retained in both clusters, but are different between them. This could indicate that they have been preserved because they are important for the regulation of those genes, but control different patterns of expression, and are, hence, an example for the process of subfunctionalization of the duplicated "daughter" copies of the genes.

Chiu et al. (2002) did not observe the same pattern of conservation in zebrafish HoxA clusters. These differences might be due to a different method of identifying CNS sequences. Chiu et al. (2002) described, by comparison of human and horn shark HoxA clusters, a great number of Phylogenetic Footprints (PFs). These are defined as short blocks of noncoding DNA, typically 6 bp or more, that are $100 \%$ conserved in two taxa that have diverged at least 250 million years ago (Tagle et al. 1988; Blanchette and Tompa 2002). Among PFs, they described as Phylogenetic Footprint Clusters (PFCs) those that were found close to each other (within 200 $\mathrm{bp}$ ) and located at comparable distances from the gene that is located $3^{\prime}$ of each intergenic region. They found only a small number of PFCs to be present in at least one of the two zebrafish HoxA clusters. They concluded that the essential Hox gene functions in zebrafish are performed with different cisregulatory elements (e.g., phenogenetic drift; Weiss and Fullerton 2000) from those of the ancestral gene, with cis elements highly conserved in horn shark and human. We defined a sequence as a CNS using the following criteria (see Methods) (1) identity over $60 \%$ in at least four out of eight clusters; (2) presence in at least two species known to have only one HoxA cluster (horn shark, human, mouse; see Fig. 1), and (3) a minimum length of 50 base pairs (bp). We therefore identified a smaller number of longer conserved elements, which are shared by a higher number of species/clusters. Moreover, because of the fact that many trans-regulatory elements recognize a core sequence that is even shorter than 6 bp and with a certain degree of tolerance, we accepted a 95\% lower threshold for the short highly conserved sequences we described (column 10 in Table 2).

\section{Regulatory Elements in Introns}

Intronic sequences are typically not conserved among evolutionarily diverged species. A clear exception to this rule are the HB1 elements, believed to be binding sites for several homeoproteins (Haerry and Gehring 1996, 1997). Our analyses show that the HB1 elements, which so far have been described only in the introns of the Hox 4 and 7 genes, are present also in the intron of the Hox 11 gene in the HoxA cluster (in both HoxA $\alpha$ and HoxA $\beta$ in zebrafish). The Hox4, 7, and 11 genes are expressed in different regions of the developing embryos (rhombomeres 6 and 7 in the hindbrain for Hox 4 paralogous group, thoracic region for Hox 7, and caudal region for Hox 11) and at different times of development. The spatial regular redundancy of HB1 elements in Hox clusters might be related to the different timing of activation of groups of Hox genes (anterior, central, and caudal) in the developing embryo. It would be of interest to better characterize the function of different HB1 elements within the same Hox cluster. Moreover, it would be important to know if other Hox clusters also show a similar pattern as the HoxA clusters concerning HB1 regulatory elements.

A long (over $600 \mathrm{bp}$ ) stretch of intron of gene Hox 2 is $60-70 \%$, and is conserved among all the species included in this comparison. Part of this sequence matches a previously described POU protein binding site (Verrijzer et al. 1992). The overexpression of homeoprotein POU2 rescues zebrafish Krx20 and valentino mutants (Hauptmann et al. 2002) that are caused by disrupted Hox2-related patterning of rhombomeres $3 / 5$. It seems likely that Hox 2 expression and function is related to the conservation of the putative regulatory element in its intron.

\section{Known Conserved Regions and Regulatory Elements}

The reliability of our results was confirmed by the observation that some of the highly conserved, possibly functional, noncoding regions that we have identified have been previously described as regulatory elements (column 11 in Table 2). Moreover, many of them contain homeoprotein binding sites that are believed to be responsible for Hox gene regulation (column 12 in Table 2). It is reasonable to assume that the elements that are evolutionarily conserved are the ones that regulatory proteins bind to, and this agrees with the evidence that other classes of homeobox genes are responsible for Hox genes regulation. Currently, four groups of transcriptional regulators have been identified that directly regulate Hox gene expression in the vertebrate embryo: retinoic acid receptors, Krx20, members of the Pbx/exd family, and the Hox genes themselves (reviewed by Lufkin 1997). Because Hox genes 
A

$\begin{array}{ll}\text { human A2 } & \text { CACCCACGC } \\ \text { mouse A2 } & \text { CACCCACGC } \\ \text { tilapia A2 } & \text { CACCCACTC } \\ \text { pufferfish A2 } & \text { CACCCACTC } \\ \text { mouse B2 } & \text { CACCCACGC } \\ \text { pufferfish B2 } & \text { CGCCCACAC } \\ \text { human B2 } & \text { CCACCACAC } \\ \text { chick B2 } & \text { CACCCACAC } \\ & \\ \text { consensus } & \star \star-\star \star \star \star-\star\end{array}$

B

$\begin{array}{ll}\text { human box a } & \text { CTGACAAAGCCT } \\ \text { mouse box a } & \text { CTGACAAAGCCC } \\ \text { tilapia box a } & \text { CACACAAAGCCT } \\ \text { pufferfish box a } & \text { GACACAAAGCCT }\end{array}$

consensus

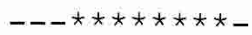

Figure 7 Alignment of known regulatory elements. $(A)$ Sequence of Krx20 binding sites in different species. Krox20 binding sites are involved in Hox2 regulation and they are conserved in HoxA and B clusters from human, mouse, pufferfish, and HoxA from tilapia. Both Krx20 and the "box a" are widely conserved. The degree of identity is $67 \%$ among the species in this comparison. (B) Alignment of sequences of the "box a" motif.

have a colinear temporal pattern of differential expression (i.e., HoxA1 is expressed before HoxA2, and so on), further studies on homeoprotein binding sites are necessary to define if and how Hox genes expressed earlier in embryo development could regulate the expression of Hox genes expressed later.

It would be particularly interesting to test some of the so far undescribed conserved noncoding regions that we have identified through this comparative genomic approach for a possible functional role in the activation and regulation of Hox genes. Because functional studies involve a great deal of effort, for example, transgenic animals, it is critical to reduce the number of possible candidates for regulatory function. Sequencing projects of whole genomes (e.g., pufferfish, zebrafish, medaka) offer new possibilities for comparative genomic approaches to study distantly related organisms to uncover putative regulatory elements. Moreover, using distantly related genome comparisons between teleosts and, for example, mammals or amphioxus, highlights the divergence in gene regulation of paralogous genes that evolved subsequent to gene duplication. It is still a subject of discussion whether paralogous genes in ray-finned fishes are due to an early whole genome duplication (Meyer and Schartl 1999; Taylor et al. 2001), or rather to several independent smaller scale duplication events (Robinson-Rechavi et al. 2001). One of the primary mechanisms by which subfunctionalization of duplicated genes occurs may be through a change in their regulatory elements, whereby mutations or differences in deletions in these elements can lead to differential expression patterns of duplicated genes (Force et al. 1999). The comparison of distantly related genomes may indicate which duplicated

genes have divergent regulatory sequences in comparison to organisms for which such a duplication did not occur, for example, mammals. This, in turn, would provide a method by which to elucidate different evolutionarily new functions for duplicated genes.

\section{METHODS}

The Hox clusters included in this study are: tilapia (Oreo-

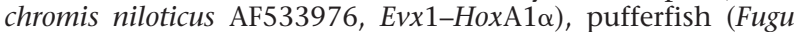
rubripes, JGI public database http://www.jgi.doe.gov/ programs/fugu/fugu_mainpage.html, HoxA $13 \alpha-H o x A 1 \alpha)$, striped bass (Morone saxatilis AF089743, HoxA10 $\alpha-H o x A 4 \alpha$ ), zebrafish (Danio rerio AC107365, Evx $1-H o x \mathrm{~A} 1 \alpha$ and AC107364, HoxA13 $\beta-$ HoxA2 $\beta$ ), horn shark (Heterodontus francisci AF224262 and AF479755 HoxM13-HoxM1, corresponding to HoxA; Kim et al. 2000), mouse (Mus musculus AC021667, HoxA13-HoxA1), and Homo sapiens (AC004079, AC004080, and AC010990, Evx1-HoxA1).

The tilapia HoxA $\alpha$ cluster sequence (Malaga-Trillo and Meyer 2001) has been used as the template sequence to which the others are compared. It has been filtered for repetitive and other "junk" elements through RepeatMasker, available at University of Washington Genome Center (http:// ftp.genome.washington.edu/cgi-bin/RepeatMasker/).

The alignment has been performed using the program MultiPipMaker available at http://bio.cse.psu.edu/pipmaker/. PipMaker (Schwartz et al. 2000) computes alignments of similar regions in two or more DNA sequences. The resulting alignments are summarized with a "percent identity plot", or "pip" for short. All pair-wise alignments with the first sequence are computed and then returned as interleaved pips, and it is possible to compute a true multiple alignment of the input sequences to produce a nucleotide-level view of the results. The alignment engine is BLASTZ, which is an experimental variant of the Gapped BLAST program (Altschul et al. 1997; Zhang et al. 1998).

Loots et al. (2000) defined conserved noncoding sequences (CNSs) as conserved noncoding elements with greater or equal to $70 \%$ identity over at least $100 \mathrm{bp}$ between humans and the mouse. Because we used eight clusters from seven species more evolutionarily divergent than only humans and the mouse, the following criteria have been used to define CNSs: identity over $60 \%$ in at least four out of eight clusters; presence in at least two species known to have only one HoxA cluster (horn shark, humans, mouse; Fig. 1) and minimum length of 50 base pairs (bp). Despite this, when taking into account only the comparison between humans and the mouse, our CNSs also fulfill the definition from Loots et al. (2000). CNSs have been tested in BLASTN (http:// www.ncbi.nlm.nih.gov/BLAST/) to confirm that they are specific to Hox clusters.

Within such sequences, stretches between 95\% and $100 \%$ identity and six nucleotides or more in length, conserved among at least six out of seven examined clusters, have received particular attention. The stretches over 95\% identity within CNSs have been used to screen the transfac database (http://transfac.gbf.de/TRANSFAC/) to determine if they have been already described as transcription factors binding sites in similar or different biological context.

\section{ACKNOWLEDGMENTS}

This work has been supported by a grant of the Deutsche Forschungsgemeinschaft (to A.M.) and by a Marie-Curie fellowship to S.S. The authors thank E. Malaga-Trillo and other members of the Meyer-Lab for library screening, many members of the DOE Joint Genome Institute (JGI) for DNA sequencing, and C. Klingenberg for reviewing the manuscript. Part of this work was performed under the auspices of the U.S.

\section{Genome Research}


Department of Energy, Office of Biological and Environmental Research, Lawrence Berkeley National Laboratory, under Contract No. DE-AC03-76SF00098.

The publication costs of this article were defrayed in part by payment of page charges. This article must therefore be hereby marked "advertisement" in accordance with 18 USC section 1734 solely to indicate this fact.

\section{REFERENCES}

Altschul, S.F., Madden, T.L., Schaffer, A.A., Zhang, J., Zhang, Z., Miller, W., and Lipman, D.J. 1997. Gapped BLAST and PSI-BLAST: A new generation of protein database search programs. Nucleic Acids Res. 25: 3389-3402.

Amores, A., Force, A., Yan, Y.-L., Joly, L., Amemiya, C., Fritz, A., Ho, R.K., Langeland, J., Prince, V., Wang, Y.-L., et al. 1998. Zebrafish Hox clusters and vertebrate genome evolution. Science 282: 1711-1714.

Aparicio, S., Morrison, A., Gould, A., Gilthorpe, J., Chaudhuri, C., Rigby, P., Krumlauf, R., and Brenner, S. 1995. Detecting conserved regulatory elements with the model genome of the Japanese pufferfish, Fugu rubripes. Proc. Natl. Acad. Sci. 92: 1684-1688.

Aparicio, S., Hawker, K., Cottage, A., Mikawa, Y., Zuo, L., Venkatesh, B., Chen, E., Krumlauf, R., and Brenner, S. 1997. Organization of the Fugu rubripes Hox clusters: Evidence for continuing evolution of vertebrate Hox complexes. Nat. Genet. 16: 79-83.

Asif, T.C., Cook, L.L., Delehaunty, K.D., Fewell, G.A., Fulton, L.A., Fulton, R.S., Graves, T.A., Hillier, L.W., Mardis, E.R., McPherson, J.D., et al. 2002. Initial sequencing and comparative analysis of the mouse genome. Nature 420: 520-562.

Bergman, C.M. and Kreitman, M. 2001. Analysis of conserved noncoding DNA in Drosophila reveals similar constraints in intergenic and intronic sequences. Genome Res. 11: 1335-1345.

Blanchette, M. and Tompa, M. 2002. Discovery of regulatory elements by a computational method for phylogenetic footprinting. Genome Res. 12: 739-748.

Brenner, S., Elgar, G., Sandford, R., Macrae, A., Venkatesh, B., and Aparicio, S. 1993. Characterization of the pufferfish (Fugu) genome as a compact model vertebrate genome. Nature 366: $265-268$.

Brenner, S., Venkatesh, B., Yap, W.H., Chou, C.F., Tay, A., Ponniah, S., Wang, Y., and Tan, Y.H. 2002. Conserved regulation of the lymphocyte-specific expression of lck in the Fugu and mammals. Proc. Natl. Acad. Sci. 99: 2936-2941.

Bucher, P. 1990. Weight matrix description of four eukaryotic RNA polymerase II promoter elements derived from 502 unrelated promoter sequences. J. Mol. Biol. 212: 563-578.

Carroll, S., Grenier, J., and Weatherbee, S. 2001. From DNA to diversity-Molecular genetics and the evolution of animal design. Blackwell Science, Malden, MA.

Catron, K.M., Iler, N., and Abate, C. 1993. Nucleotides flanking a conserved TAAT core dictate the DNA binding specificity of three murine homeodomain proteins. Mol. Cell. Biol. 13: 2354-2365.

Chiu, C.H., Amemiya, C., Dewar, K., Kim, C.B., Ruddle, F.H., and Wagner, G.P. 2002. Molecular evolution of the HoxA cluster in the three major gnathostome lineages. Proc. Natl. Acad. Sci. 99: 5492-5497.

Chu, D., Kakazu, N., Gorrin-Rivas, M., Lu, H., Kawata, M., Abe, T., Ueda, K., and Adachi, Y. 2001. Cloning and characterization of LUN, a novel ring finger protein that is highly expressed in lung and specifically binds to a palindromic sequence. J. Biol. Chem. 276: 14004-14013.

Clark, A.G. 2001. The search for meaning in noncoding DNA. Genome Res. 11: 1319-1320.

Cliften, P.F., Hillier, L.W., Fulton, L., Graves, T., Miner, T., Gish, W.R., Waterston, R.H., and Johnston, M. 2001. Surveying Saccharomyces genomes to identify functional elements by comparative DNA sequence analysis. Genome Res. 11: 1175-1186.

Doerksen, L.F., Bhattacharya, A., Kannan, P., Pratt, D., and Tainsky, M.A. 1996. Functional interaction between a RARE and an AP-2 binding site in the regulation of the human HOX A4 gene promoter. Nucleic Acids Res. 24: 2849-2856.

Duboule, D. and Dollé, P. 1989. The structural and functional organization of the murine $H O X$ gene family resembles that of Drosophila homeotic genes. EMBO J. 8: 1497-1505.

Ekker, S.C., Young, K.E., von Kessler, D.P. and Beachy, P.A. 1991. Optimal DNA sequence recognition by the ultrabithorax homeodomain of Drosophila. EMBO J. 10: 1179-1186.
Ekker, S.C., Jackson, D.G., von Kessler, D.P., Sun, B.I., Young, K.E., and Beachy, P.A. 1994. The degree of variation in DNA sequence recognition among four Drosophila homeotic proteins. EMBO J. 13: $3551-3560$.

Epstein, J., Cai, J., Glaser, T., Jepeal, L., and Maas, R. 1994. Identification of a Pax paired domain recognition sequence and evidence for DNA-dependent conformational changes. J. Biol. Chem. 269: 8355-8361.

Ferrier, D.E., Minguillon, C., Holland, P.W., and Garcia-Fernandez, J. 2000. The amphioxus Hox cluster: Deuterostome posterior flexibility and Hox14. Evol. Dev. 2: 284-293.

Force, A., Lynch, M., Pickett, F.B., Amores, A., Yan, Y.L., and Postlethwait, J. 1999. Preservation of duplicate genes by complementary, degenerative mutations. Genetics 151: $1531-1545$

Frasch, M., Chen, X., and Lufkin, T. 1995. Evolutionary-conserved enhancers direct region-specific expression of the murine Hoxaand Hoxa-2 loci in both mice and Drosophila. Development 121: 957-974.

Garcia-Fernandez, J. and Holland, P.W. 1994. Archetypal organization of the amphioxus Hox gene cluster. Nature 370: $563-566$.

Gehring, W.J. 1993. Exploring the homeobox. Gene 135: 215-221.

Grange, T., Roux, J., Rigaud, G., and Pictet, R. 1991. Cell-type specific activity of two glucocorticoid responsive units of rat tyrosine aminotransferase gene is associated with multiple binding sites for C/EBP and a novel liver-specific nuclear factor. Nucleic Acids Res. 19: 131-139.

Haerry, T.E. and Gehring, W.J. 1996. Intron of the mouse Hoxa-7 gene contains conserved homeodomain binding sites that can function as an enhancer element in Drosophila. Proc. Natl. Acad. Sci. 93: 13884-13889.

. 1997. A conserved cluster of homeodomain binding sites in the mouse Hoxa-4 intron functions in Drosophila embryos as an enhancer that is directly regulated by Ultrabithorax. Dev. Biol. 186: $1-15$.

Hardison, R.C. 2000. Conserved noncoding sequences are reliable guides to regulatory elements. Trends Genet. 16: 369-372.

Hardison, R.C., Oeltjen, J., and Miller, W. 1997. Long human-mouse sequence alignments reveal novel regulatory elements: A reason to sequence the mouse genome. Genome Res. 7: 959-966.

Hauptmann, G., Belting, H.G., Wolke, U., Lunde, K., Soll, I., Abdelilah-Seyfried, S., Prince, V., and Driever, W. 2002. spiel ohne grenzen/pou2 is required for zebrafish hindbrain segmentation. Development 129: 1645-1655.

Hinegardner, R. 1976. The cellular DNA content of sharks, rays and some other fishes. Comp. Biochem. Physiol. B 55: 367-370.

Holland, P.W. 1997. Vertebrate evolution: Something fishy about Hox genes. Curr. Biol. 7: R570-R572.

Kim, C.-B., Amemiya, C., Bailey, W., Kawasaki, K., Mezey, J., Miller, W., Minoshima, S., Shimizu, N., Wagner, G., and Ruddle, F. 2000. Hox cluster genomics in the horn shark, Heterodontus francisci. Proc. Natl. Acad. Sci. 97: 1655-1660.

Knittel, T., Kessel, M., Kim, M.H., and Gruss, P. 1995. A conserved enhancer of the human and murine HoxA-7 gene specifies the anterior boundary of expression during embryonal development. Development 121: 1077-1088.

Krumlauf, R. 1994. Hox genes in vertebrate development. Cell 78: $191-201$

Langston, A.W., Thompson, J.R., and Gudas, L.J. 1997. Retinoic acid-responsive enhancers located 3' of the Hox A and Hox B homeobox gene clusters. Functional analysis. J. Biol. Chem. 272: $2167-2175$.

Loots, G.G., Locksley, R.M., Blankespoor, C.M., Wang, Z.E., Miller, W., Rubin, E.M., and Frazer, K.A. 2000. Identification of a coordinate regulator of interleukins 4,13 , and 5 by cross-species sequence comparisons. Science 288: 136-140.

Lufkin, T. 1997. Transcriptional regulation of vertebrate Hox genes during embryogenesis. Crit. Rev. Eukaryot. Gene Expr. 7: 195213.

Maconochie, M., Nonchev, S., Morrison, A., and Krumlauf, R. 1996. Paralogous Hox genes: Function and regulation. Annu. Rev. Genet. 30: 529-556.

Malaga-Trillo, E. and Meyer, A. 2001. Genome duplication and accelerated evolution of Hox genes and cluster architecture in teleosts fishes. Am. Zool. 41: 676-686.

Manzanares, M., Wada, H., Itasaki, N., Trainor, P.A., Krumlauf, R., and Holland, P.W.H. 2000. Conservation and elaboration of Hox gene regulation during evolution of the vertebrate head. Nature 408: $854-857$. 
Santini et al.

Margalit, Y., Yarus, S., Shapira, E., Gruenbaum, Y., and Fainsod, A. 1993. Isolation and characterization of target sequences of the chicken CdxA homeobox gene. Nucleic Acids Res. 21: 4915-4922.

Meyer, A. 1998. Hox gene variation and evolution. Nature 391: 225-228.

Meyer, A. and Malaga-Trillo, E. 1999. More fishy tales about Hox genes. Curr. Biol. 9: R210-R213.

Meyer, A. and Schartl, M. 1999. Gene and genome duplications in vertebrates: The one-to-four (-to-eight in fish) rule and the evolution of novel gene functions. Curr. Opin. Cell. Biol. 11: $699-704$

Moran, J.V., DeBerardinis, R.J., and Kazazian Jr., H.H. 1999. Exon shuffling by L1 retrotransposition. Science 283: 1530-1534.

Morrison, A., Chaudhuri, C., Ariza-McNaughton, L., Muchamore, I., Kuroiwa, A., and Krumlauf, R. 1995. Comparative analysis of chicken Hoxb-4 regulation in transgenic mice. Mech. Dev. 53: $47-59$.

Nonchev, S., Vesque, C., Maconochie, M., Seitanidou, T., Ariza-McNaughton, L., Frain, M., Marshall, H., Sham, M.H., Krumlauf, R., and Charnay, P. 1996. Segmental expression of Hoxa-2 in the hindbrain is directly regulated by Krox-20. Development 122: 543-554.

Odenwald, W.F., Garbern, J., Arnheiter, H., Tournier-Lasserve, E., and Lazzarini, R.A. 1989. The Hox-1.3 homeo box protein is a sequence-specific DNA-binding phosphoprotein. Genes \& Dev. 3: $158-172$.

Ohno, S. and Atkin, N.B. 1966. Comparative DNA values and chromosome complements of eight species of fishes. Chromosoma 18: 455-466.

Onyango, P., Miller, W., Lehoczky, J., Leung, C.T., Birren, B., Wheelan, S., Dewark, K., and Feinberg, A.P. 2000. Sequence and comparative analysis of the mouse 1-Megabase region orthologous to the human 11p15 imprinted domain. Genome Res. 10: 1697-1710.

Peifer, M., Karch, F., and Bender, W. 1987. The bithorax complex: Control of segmental identity. Genes \& Dev. 1: 891-898.

Pough, F.H., Janis, C.M., and Heiser, J.B. 1999. Vertebrate life. Prentice Hall, Englewood Cliffs, NJ.

Prince, V.E., Joly, L., Ekker, M., and Ho, R.K. 1998. Zebrafish Hox genes: Genomic organization and modified colinear expression patterns in the trunk. Development 125: 407-420.

Robinson-Rechavi, M., Marchand, O., Escriva, H., Bardet, P.L., Zelus, D., Hughes, S., and Laudet, V. 2001. Euteleost fish genomes are characterized by expansion of gene families. Genome Res. 11: $781-788$

Rossi, P., Karsenty, G., Roberts, A.B., Roche, N.S., Sporn, M.B., and de Crombrugghe, B. 1988. A nuclear factor 1 binding site mediates the transcriptional activation of a type I collagen promoter by transforming growth factor- $\beta$. Cell 52: 405-414

Roth, F.P., Hughes, J.D., Estep, P.W., and Church, G.M. 1998. Finding DNA regulatory motifs within unaligned noncoding sequences clustered by whole-genome mRNA quantitation. Nat. Biotechnol. 16: 939-945.

Schwartz, S., Zhang, Z., Frazer, K.A., Smit, A., Riemer, C., Bouck, J., Gibbs, R., Hardison, R., and Miller, W. 2000. PipMaker-A web server for aligning two genomic DNA sequences. Genome Res. 10: $577-586$.

Snell, E.A., Scemama, J.-L., and Stellwag, E.J. 1999. Genomic organization of the Hoxa4-Hoxa10 region from Morone saxatilis Implications for Hox gene evolution among vertebrates. J. Exp. Zool. (Mol. Dev. Evol.) 285: 41-49.

Stingo, V., Rocco, L., and Improta, R. 1989. Chromosome markers and karyology of selachians. J. Exp. Zool. Suppl. 2: 175-185.

Tagle, D.A., Koop, B.F., Goodman, M., Slightom, J.L., Hess, D.L., and
Jones, RT. 1988. Embryonic $\epsilon$ and $\gamma$ globin genes of a prosimian primate (Galago crassicaudatus). Nucleotide and amino acid sequences, developmental regulation and phylogenetic footprints. J. Mol. Biol. 203: 439-455.

Tan, D.-P., Ferrante, J., Nazarali, A., Shao, X., Kozak, C.A., Guo, V., and Nirenberg, M. 1992. Murine Hox-1.11 homeobox gene structure and expression. Proc. Natl. Acad. Sci. 89: 6280-6284.

Taylor, J.S., Van de Peer, Y., Braasch, I., and Meyer, A. 2001. Comparative genomics provides evidence for an ancient genome duplication event in fish. Philos. Trans. R. Soc. Lond. B. Biol. Sci. 356: $1661-1679$

Tiersch, T.R., Chandler, R.W., Wachtel, S.S., and Elias, S. 1989 Reference standards for flow cytometry and application in comparative studies of nuclear DNA content. Cytometry 10: $706-710$

Tomilin, N.V. 1999. Control of genes by mammalian retroposons. Int. Rev. Cytol. 186: 1-48.

Tompa, M. 2001. Identifying functional elements by comparative DNA sequence analysis. Genome Res. 11: 1143-1144.

Venkatesh, B., Gilligan, P., and Brenner, S. 2000. Fugu: A compact vertebrate reference genome. FEBS Lett. 476: 3-7.

Verrijzer, C.P., Alkema, M.J., van Weperen, W.W., Van Leeuwen, H.C., Strating, M.J., and van der Vliet, P.C. 1992. The DNA binding specificity of the bipartite POU domain and its subdomains. EMBO J. 11: 4993-5003.

Vesque, C., Maconochie, M., Nonchev, S., Ariza-McNaughton, L., Kuroiwa, A., Charnay, P., and Krumlauf, R. 1996. Hoxb-2 transcriptional activation in rhombomeres 3 and 5 requires an evolutionarily conserved cis-acting element in addition to the Krox-20 binding site. EMBO J. 15: 5383-5396.

Vinogradov, A.E. 1998. Genome size and GC-percent in vertebrates as determined by flow cytometry: The triangular relationship. Cytometry 31: 100-109.

Wasserman, W.W., Palumbo, M., Thompson, W., Fickett, J.W., and Lawrence, C.E. 2000. Human-mouse genome comparisons to locate regulatory sites. Nat. Genet. 26: 225-228.

Weiss, K.M. and Fullerton, S.M. 2000. Phenogenetic drift and the evolution of genotype-phenotype relationships. Theor. Popul. Biol. 57: 187-195.

Wittbrodt, J., Meyer, A., and Schartl, M. 1998. More genes in fish? BioEssays 20: $511-515$.

Woods, D.B., Ghysdael, J., and Owen, M.J. 1992. Identification of nucleotide preferences in DNA sequences recognized specifically by c-ETS-1 protein. Nucleic Acids Res. 20: 699-704.

Yanagisawa, S. and Schmidt, R.J. 1999. Diversity and similarity among recognition sequence of Dof transcription factors. Plant J. 17: 209-214.

Zhang, Z., Berman, P., and Miller, W. 1998. Alignments without low-scoring regions. J. Comput. Biol. 5: 197-210.

\section{WEB SITE REFERENCES}

http://www.jgi.doe.gov/programs/fugu/fugu_mainpage.html; JGI fugu project homepage.

http://ftp.genome.washington.edu/cgi-bin/RepeatMasker/; RepeatMasker homepage.

http://bio.cse.psu.edu/pipmaker/; PipMaker homepage.

http://transfac.gbf.de/TRANSFAC/; Transfac database homepage.

http://www.ncbi.nlm.nih.gov/BLAST/; BLAST homepage.

Received August 8, 2002; accepted in revised form March 24, 2003.

\section{Genome Research}


Genome Research 13: 1111-1122 (2003)

Evolutionary Conservation of Regulatory Elements in Vertebrate Hox Gene Clusters

Simona Santini, Jeffrey L. Boore, and Axel Meyer

The GenBank accession number listed beneath the Abstract of this article was incorrect. The correct number is AF533976. 


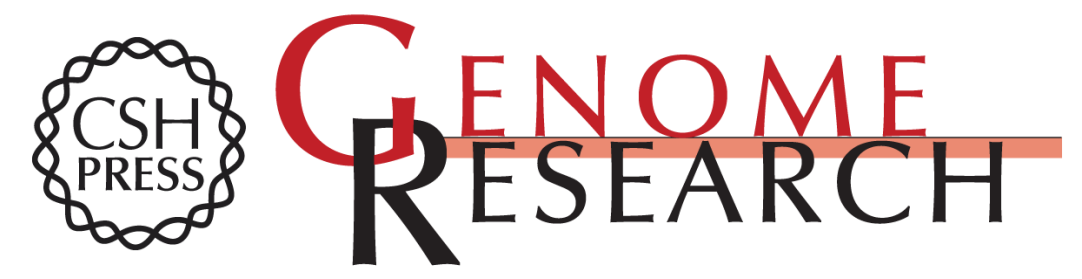

\section{Evolutionary Conservation of Regulatory Elements in Vertebrate Hox Gene Clusters}

Simona Santini, Jeffrey L. Boore and Axel Meyer

Genome Res. 2003 13: 1111-1122

Access the most recent version at doi:10.1101/gr.700503

\section{Supplemental http://genome.cshlp.org/content/suppl/2003/06/09/13.6a.1111.DC1 Material}

Related Content Correction for Volume 13, p. 1111

Genome Res. August , 2003 13: 1973

References This article cites 76 articles, 30 of which can be accessed free at: http://genome.cshlp.org/content/13/6a/1111.full.html\#ref-list-1

Articles cited in:

http://genome.cshlp.org/content/13/6a/1111.full.html\#related-urls

\section{License}

Email Alerting Receive free email alerts when new articles cite this article - sign up in the box at the Service top right corner of the article or click here.

\section{Affordable, Accurate Sequencing.}

